\title{
Evaluation of Abnormal Urine Drug Screens Among Patients With Chronic Non-Malignant Pain Treated With Opioids
}

\author{
Opioids are commonly used in chron- \\ ic pain management. Their role in chronic \\ pain is met with controversy, with reports of \\ abuse. Many studies have shown that urine \\ drug screens can detect inappropriate opioid \\ use or illicit drug use among patients receiv- \\ ing opioids for chronic pain.
}

Sairam Atluri, MD, and Gururau Sudarshan, MD
In this study, failed urine drug screens of 89 patients in an interventional pain management practice were analyzed. The results showed that $55 \%$ were not taking the prescribed opioid, whereas $39 \%$ were taking opioids which were not prescribed. In addition, $46 \%$ of the patients were using illicit drugs.
Urine drug screens can be very useful in preventing opioid abuse. Along with illicit drug use, not taking the opioid as prescribed or taking other opioids which are not prescribed can also be detected.

Keywords: Chronic pain, prescription opioid abuse, urine drug screens, opioids
Chronic non-malignant pain is highly prevalent in our society $(1,2)$. Opioids are increasingly being utilized in managing chronic pain (3). They play an important role in chronic pain management especially when other modalities like physical therapy, psychological therapy, nonopioid drug therapy, surgery, or interventional pain management fail to provide adequate relief. However, their role continues to be controversial due to the risk of abuse and addiction.

Numerous studies have documented the relatively high incidences of opioid abuse in chronic non-malignant pain (4-7). Identifying abuse of prescription opioids among legitimate CNMP patients is challenging. Experts have established that urine drug screens (UDS) can be useful in detection of prescription opioid abuse $(4,5,7)$. UDS's are currently one of the best ways to diagnose prescription opioid abuse. They are superior to monitoring abuse behaviors in these patients (4-7). Additionally, Manchikanti et al (5) have shown that UDS's are useful to detect prescription opioid abuse even in patients without any history of substance abuse.

From Tri-State Pain Management Institute, Love land, $\mathrm{OH}$, and Cincinnati Pain Management Consultants, Cincinnati, $\mathrm{OH}$. Address Correspondence: Sairam Atluri MD, Tri-State Pain Management Institute, 10160 Meadowknoll Dr, Loveland OH-45140. E-mail: atluri_ps@sprynet.com

Funding: There was no external funding in preparation of this manuscript.

\section{Methods}

Patients in an interventional pain management setting who failed the UDS were included in the study. All patients were complaining of CNMP and were treated with opioids in conjunction with interventional pain management. $\mathrm{Pa}$ tients were subjected to the UDS because of suspected abuse behaviors. Some were randomly selected to undergo UDS. Prior to informing patients about the UDS, a questionnaire was administered. The patients were asked if they were taking their prescribed opioid regularly in the past one week. Those who did not report regular use were not subjected to the UDS. Patients were then asked if they were taking opioids exclusively from prescribing physicians. If patients had a negative answer to this question, UDS was not administered. They were also asked if they had smoked marijuana recently. Only those patients who denied recent marijuana use were subjected to the UDS. Additionally, queries also included if they were using any illicit drugs like cocaine, heroin, amphetamines or phencyclidine (PCP). Barbiturate and benzodiazepine use was also questioned. No one was allowed to accompany the individual while producing the urine sample. Once the patients were informed about the UDS, they were not allowed to leave the clinic until they could provide the specimen.

The urine sample was subjected to two tests, namely Drug Screen-9 (DS-9) by EMIT assay and Opioid confirmation by Gas Chromatography and Mass Spectrometry (OPGCMS). DS-9 test which is a screening test, identifies the following 9 substances. The cutoff limits in $\mathrm{ng} / \mathrm{ml}$ are listed below:

1. opioids $-300 \mathrm{ng} / \mathrm{mL}$

2. propoxyphene $-300 \mathrm{ng} / \mathrm{mL}$

3. methadone $-300 \mathrm{ng} / \mathrm{mL}$

4. cocaine - $300 \mathrm{ng} / \mathrm{mL}$

5. marijuana $-50 \mathrm{ng} / \mathrm{mL}$

6. PCP - $50 \mathrm{ng} / \mathrm{mL}$

7. barbiturates $-200 \mathrm{ng} / \mathrm{mL}$

8. amphetamines - $1000 \mathrm{ng} / \mathrm{mL}$

9. benzodiazepines $-200 \mathrm{ng} / \mathrm{mL}$

In this test, the category of opioids screened for oxycodone, hydrocodone, hydromorphone, morphine and codeine. If a patient was on any of these, the DS-9 test would report positive for 'opioids' but it will not specifically identify the opioid. Even though methadone and propoxyphene are opioids, they are not reported as such in this test. Instead they are reported specifically as methadone and propoxyphene. Only if opioids were positive on this DS-9, then OPGCMS done.

OPGCMS test unlike the DS-9 is confirmatory test and is a gold standard for identifying opioid (the cut off limit is $150 \mathrm{ng} / \mathrm{ml}$ ).
1. oxycodone
2. hydrocodone
3. hydromorphone
4. morphine
5. codeine 
If a patient is taking any of the above 5 opioids, this test would specifically report the opioid. For instance if the patient is on OxyContin, the test would be positive for oxycodone. Because hydrocoa patient is on hydrocodone, both hydrocodone and hydromorphone may be positive. However if the patient is on hydromorphone, only hydromorphone should be positive. Similar interaction occurs between codeine and morphine because codeine is metabolized to morphine. Sometimes opioids are positive on DS-9 but negative on OPGCMS. These findings were ignored as there was no logical explanation. These interactions were taken into consideration during interpretation of UDS.

The following criteria constituted abnormal urine UDS.

1. The presence of any illicit drugs i.e., cocaine, heroin, phencyclidine, amphetamine

2. The presence of marijuana (if not reported prior to testing)

3. The presence of opioids other than those prescribed by the clinic and if not reported by the subjects prior to drug screening

4. The inability to detect a prescribed opioid when patient reports of recent and regular use on the pre drug screen questionnaire

5. The refusal to take the urine drug screen

6. If there is evidence of tampering with the urine specimen i.e., abnormal done is metabolized to hydromorphone, if

specific gravity, urinary creatinine and $\mathrm{Ph}$

\section{RESULTS}

Eighty-nine patients with abnormal UDS based on the above described criteria were analyzed. Table 1 shows the results of abnormal UDS. Table 2 illustrates the proportion of patients with illicit drugs.

\section{Discussion}

This report describes the importance of using UDS to identify patients with inappropriate opioid use among patients with genuine chronic pain. Previous reports by Manchikanti et al $(4,5)$ have shown that UDS are helpful in identifying patients who are using illicit drugs concurrently with opioids. In our study sample, $46 \%$ of patients with abnormal results of UDS were using illicit drugs along with prescription opioids. Fifty five (Please check) percent had abnormal UDS because they were not taking the opioid as prescribed and falsely reported in the predrug screen questionnaire that they were. Thirty nine percent had abnormal UDS because they were taking opioids from other sources and didn't reveal the accurate intake, despite the predrug screen questionnaire. Predrug screen questionnaire and the addition of OPGCMS to DS-9 seem to have a role in preventing inappropriate opioid use.

OPGCMS is useful because if, for instance, a patient is obtaining morphine from one source and oxycodone from another source, this test would re-

Table 1. Abnormal UDS

\begin{tabular}{|l|c|}
\hline \multicolumn{1}{|c|}{ CATEGORY } & PERCENTAGE \\
\hline Presence of illicit drugs & $46 \%(41)$ \\
\hline Absence of prescribed opioid & $55 \%(49)$ \\
\hline Presence of opioids from other sources & $39 \%(35)$ \\
\hline Patient refusing to take UDS & $5 \%(4)$ \\
\hline Patient adulterating the specimen & $1 \%(1)$ \\
\hline
\end{tabular}

These categories were not mutually exclusive. Some patients had more than one. Therefore, these totals do not equal to 89.

$\overline{\text { Table 2. Illustration of proportion of various illicit drugs among those with }}$ abnormal UDS

\begin{tabular}{|l|c|}
\hline \multicolumn{1}{|c|}{ Name of the Illicit Drug } & Percentage \\
\hline Marijuana only & $32 \%(29)$ \\
\hline Cocaine only & $7 \%(6)$ \\
\hline Marijuana \& Cocaine & $7 \%(6)$ \\
\hline No illicit drugs & $54 \%(48)$ \\
\hline
\end{tabular}

port both specifically, unlike DS-9 which would report positive for 'opioids'. Thus, doctor shopping wouldn't be detected. This is especially useful in states where the state does not monitor prescription opioid use unlike Kentucky which has KASPER (Kentucky All Schedule Prescription Electronic Reporting), Nevada, and Utah.

Most patients (39\%) with illicit drug use were abusing marijuana. Only those patients who attempted to conceal marijuana use were included in the study. A significant proportion (14\%) were also using cocaine.

There is no consensus even among experts about what tests need to be ordered in the UDS and also about when and how many drug screens should be done. Some recommend doing UDS on every patient at every visit (7). They cite that the high economic burden of abuse to the society justifies the cost of frequent UDS. Other experts feel that only drug screening without confirmation would suffice for cost considerations. Further research into this important topic is desperately needed.

This study may be criticized for including mostly patients of suspected abuse. Further, the study also has not included a number of patients who have provided accurate information with regards to licit or illicit drug use. Thus, this study does not provide any reliable statistics on the proportion of patients abusing prescription drugs or using illicit drugs in interventional pain management settings. Further, we are unable to determine based on this evaluation, prevalence of prescription drug abuse or illicit drug use in patients with or without controlled substance abuse.

\section{ConcLusion}

It is important to screen for prescription opioid abuse primarily because it can have negative consequences for patients, physicians, and the society. Urine drug screens have a useful role in monitoring patients with chronic non-malignant pain receiving opioid therapy. Currently, they are probably one of the best ways to identify abuse among patients with chronic pain. UDS's can not only aid us in the detection of illicit drugs but can also reveal if the patient is taking the opioid as prescribed or if he/she is taking other opioids which are not prescribed by us. 


\section{Author Affiliation \\ Sairam Atluri MD}

Tri-State Pain Management Institute 10160 Meadowknoll Dr

Loveland, OH 45140

E-mail: atluri_ps@sprynet.com

Gururau Sudarshan, MD

Cincinnati Pain Management Consultants

10505 Montgomery Road

Cincinnati, OH 45140

E-mail: gsudarshan@cinci.rr.com

\section{RefERENCES}

1. Verhaak PF, Kerssens JJ, Dekker J et al. Prevalence of chronic pain disorder among adults: a review of the literature. Pain 1998; 77:231-239.

2. Gureje $O$, Von Korff M, Simon GE et al. Persistent pain and well-being: A World Health Organization Study in Primary Care. JAMA 1998; 280:147-151.

3. Joranson DE, Ryan KM, Gilson AM et al. Trends in medical use and abuse of opioid analgesics. JAMA 2000; 283:1710-1714.

4. Manchikanti L, Pampati V, Damron K et al. Prevalence of opioid abuse in interven- tional pain medicine practice settings: A randomized clinical evaluation: Pain Physician 2001; 4:358-365.

5. Manchikanti L, Pampati V, Damron K et al. Prevalence of illicit drug use in patients without controlled substance abuse in interventional pain management. Pain Physician 2003; 6:173-178.

6. Chabal C, Erjavec M, Jacobson L et al. Prescription opiate abuse in chronic pain patients: Clinical criteria, incidence, and predictors. Clin J Pain 1997; 13:150-155.

7. Katz N, Fanciullo G. Role of urine toxicology testing in the management of chronic opioid therapy. Clin J Pain 2002; 18:S76-S82. 
